\title{
Amyloid and the lower respiratory tract
}

Amyloidosis is characterised by the deposition in many tissues of a histochemically specific substance called amyloid, which is usually recognised by its staining reaction with congo red and the subsequent demonstration of green dichroism when examined under polarised light. ${ }^{1}$

The classification of amyloidosis has evolved arbitrarily over the last 50 years on the basis of the sites of deposition and the presence or absence of other diseases. The term "generalised" or "systemic" has been used when amyloid has been present in multiple anatomical systems and "localised" when it has been confined to one. The term "secondary" has been applied to patients with a coexistent disease that has appeared to be causally related, including malignancy, syphilis, rheumatoid arthritis, tuberculosis, and multiple myeloma. ${ }^{2}$ In the absence of such disease the amyloidosis has been designated "primary." The first detailed classification was proposed in 1935 and included four groups: (1) primary, (2) secondary, (3) secondary to multiple myeloma, and (4) localised masses. At that time the localised form was known to affect the eye, bladder, urethra, pharynx, tongue, and respiratory tract. $^{3}$

The first report of amyloid localised to the lower respiratory tract was by Lesser in $1877 .{ }^{4}$ Subsequent sporadic reporting of respiratory amyloid has led to the use of many classifications and descriptive titles. A further complication is the fact that many subgroups of respiratory amyloid exist and there are important differences in presenting symptoms, signs, prognosis, and management. Prowse, ${ }^{5}$ Weiss, ${ }^{6}$ Spencer, ${ }^{7}$ Wilson et al ${ }^{8}$ Himmelfarb et al, ${ }^{9}$ and Rubinow et $a^{10}$ have all extensively reviewed localised respiratory amyloid and have proposed their own classifications. These, however, are conflicting and in some instances confusing. To help clarify the matter we reviewed 157 reported cases of localised amyloidosis of the lower respiratory tract as well as the reports on respiratory lesions in generalised amyloidosis. This led us to propose the new classification set out in the table, which we believe to be both unambiguous and helpful in the clinical approach to this disease as well as adequately describing all the cases we reviewed.
Lower respiratory tract amyloidosis

A Generalised (systemic) amyloidosis*

(1) Primary

(2) Secondary

B Localised amyloidosis*

(1) Primary
(a) Tracheobronchial
(b) Pulmonary (parenchymal)
(i) Multifocal submucosal plaques
(ii) Tumour-like mass
(i) Nodular-multiple or solitary
(ii) Diffuse alveolar septal

(2) Secondary

(a) Tracheobronchia-plaques or tumour form

(b) Pulmonary (parenchymal)-nodular or diffuse

${ }^{*}$ Whether or not affecting hilar or mediastinal nodes.

Although there are only a few specific reviews of reports of pulmonary lesions in primary generalised amyloidosis, most patients apparently have deposits in the lower respiratory tract. ${ }^{11}$ Histologically these $\stackrel{\varnothing}{\unrhd}$ are similar to those seen in the localised diffuse $\overrightarrow{\overrightarrow{0}}$ alveolar septal form, except for a few cases which 3 have been reported as having pulmonary nodules. ${ }^{41213}$ Secondary generalised amyloid can similarly affect the lower respiratory tract but it is less common and infiltrates the lung to a lesser extent. This is confirmed clinically as it is extremely $\underset{x}{*}$ rare for patients with generalised secondary amyloidosis to have any respiratory symptoms and the chest radiograph is usually normal. Primary generalised amyloidosis provokes an inflammatory response in the surrounding lung tissue while this is 은 unusual in the secondary form. ${ }^{14}$

In reviewing localised pulmonary amyloid we excluded any cases with demonstrable lesions in $N_{0}$ non-respiratory $\operatorname{sites}^{41213}$ and any which were reported twice by different authors. ${ }^{12}{ }^{15}$ The remain- 0 ing 157 cases were then divided into two groups, $\omega$ 126 cases of primary localised amyloidosis and 31 which we called secondary. Six of the patientso had hilar or mediastinal node enlargement. ${ }^{53-58} \mathbb{\Phi}$ In the primary group there were 57 patients? who had tracheobronchial multifocal submucosalt plaques, ${ }^{591016-28535459-90} 10$ who had tracheobronchial amyloid tumour-like masses, ${ }^{291-98} 55$ who had discrete nodules in the pulmonary parenchyma (that is, peripheral lung tissue), ${ }^{68-10142629-3655-5777}$ 
84 93 99-131 and four who had diffuse alveolar septal lesions. ${ }^{10263758}$

Under secondary localised amyloid we grouped 31 patients who had amyloid localised to the lower respiratory tract and a disease state that is known to be associated with amyloidosis. ${ }^{8916173038-44132-149}$ Among these were patients with tuberculosis, syphilis, hypergammaglobulinaemia, and neoplasia. There were 11 patients with an associăted pulmonary neoplasm. ${ }^{16} 173038-44$ In five of these patients an anaplastic or carcinoid tumour was entirely enmeshed by amyloid tissue and the possibility that the tumour cells produce amyloid has been suggested. ${ }^{38-41}$ It would be incorrect to assume therefore that a lung lesion where the biopsy specimen shows amyloid is necessarily benign. If a biopsy specimen is obtained from an isolated pulmonary lesion it is important that it is fully sectioned and examined in detail for neoplastic tissue.

Although the lymphatic system is frequently affected in generalised amyloidosis isolated deposits affecting the lymph nodes are unusual. ${ }^{31}$ There have been two case reports of isolated mediastinal node deposits but in both patients the cervical nodes were affected as well. ${ }^{3145}$ Hilar and mediastinal lymphadenopathy associated with localised pulmonary amyloid is equally rare and the two case reports in this issue ( $p 151$ and $p 153$ ) bring the total number to eight. The presence of hilar or mediastinal nodes, or both, in association with a pulmonary lesion can make the clinical picture confusing. Patients are usually investigated for a pulmonary neoplasm and occasionally receive inappropriate treatment as a result.

The diagnosis of amyloid in the respiratory tract may be difficult. It can simulate carcinoma, pulmonary oedema, diffuse lung fibrosis, bronchiectasis, tuberculosis, and many other cardiothoracic diseases. To add to this problem there is the strong likelihood that tracheobronchopathia osteoplastica is a late sequela of tracheobronchial submucosal amyloid. ${ }^{17-22}$ Patients with the tracheobronchial submucosal plaques frequently present with cough, dyspnoea, stridor, or haemoptysis. The stridor and haemoptysis may become life threatening as the disease progresses. ${ }^{23}$ At bronchoscopy the submucosal plaques of amyloid are seen as ridges and stenoses and are shiny and pale owing to stretching of the overlying surface epithelium. The chest radiograph may be normal or show areas of atelectasis secondary to obstruction by amyloid lesions that are distributed radially along the proximal airways. As a result the patients frequently suffer from repeated episodes of bronchial infection and may eventually develop areas of bronchiectasis, leading to further confusion in diagnosis. 52432
In contrast, the endobronchial tumour-like masses are usually polypoid and solitary and occur only in the major bronchi. As a result the clinical features, radiographic changes, and macroscopic appearance at bronchoscopy may be indistinguishable from those of an endobronchial neoplasm. ${ }^{29}$ Local biopsies or total resection, or both, as well as a vigilant histology department may be needed to make the correct diagnosis.

Patients with parenchymal lung nodules are usually referred to the physician because of an incidental finding on their chest radiograph. Occasionally they have symptoms which are attributable to the mechanical effects of a large pulmonary mass. The pulmonary nodules are usually peripheral and subpleural and range in size from 1 to $15 \mathrm{~cm}$ in diameter. They grow slowly, may be solitary or multiple, and may affect both lungs at the same time. Up to one-third of the nodules cavitate or have calcification, adding to the difficulties of making a radiological diagnosis. ${ }^{9}{ }^{1032}$ It may also be difficult to make a histological diagnosis as a few nodules have been described as being lamellated and granulomatous. ${ }^{46}$ In the nodular (and diffuse) pulmonary form needle aspiration and transbronchial biopsies provide relatively non-invasive methods of diagnosis. ${ }^{33} 34$ Surgical resection, however, is often needed to obtain a satisfactory result.

Although the group of patients with diffuse pulmonary lesions may also present with an abnormal chest radiograph they more frequently complain of increasing dyspnoea with no obvious cause. They may have basal lung crepitations as their only clinical sign but occasionally there is an associated pleural effusion. The radiographic abnormalities and clinical features are frequently confused with those of pulmonary oedema, of both cardiac and non-cardiac origin, and with pulmonary fibrosis. The diagnosis is most frequently obtained at necropsy and microscopic sections show the amyloid tissue to be deposited in alveolar walls and septa as well as around pulmonary arterioles. ${ }^{102637}$

The effectiveness of treatment for pulmonary amyloid depends on the type. With tracheobronchial submucosal plaques, repeated treatment with bronchoscopic piecemeal resections is usually needed. ${ }^{27}$ Cure is rarely achieved and severe haemoptysis is a common complication. ${ }^{28}$ In this respect the use of bronchoscopic laser cautery may eventually prove to be a better form of treatment. Recurrence after excision of isolated masses, whether they are endobronchial or pulmonary nodules, is very rare and this is therefore the treatment of choice. ${ }^{35}$ In view of the relatively benign nature of the pulmonary nodules, however, careful observation may be all that is required if histological examination has 
already provided evidence of amyloid without total resection. This course would not be wise for a solitary nodule as it would be difficult to differentiate it from a neoplasm producing amyloid. In amyloidosis many other forms of treatment have been used, including corticosteroids, immunosuppressants, colchicine, and radiotherapy. In respiratory amyloid they have been used particularly in the management of tracheobronchial plaques and alveolar septal infiltrations, but with only limited success. ${ }^{26363747}$ Newer approaches to treatment have concentrated on drugs that break down the amyloid fibrils.

Amyloid consists of a matrix of fibrillary proteins whose unique staining properties with congo red and green birefringence with polarised light are due to the structural arrangement of the fibrils in twisted beta-pleated sheets. ${ }^{1}$ All forms of amyloid have this basic structure but the protein fibrils differ chemically. At least two major subunit proteins of amyloid, AA and $\mathrm{AL}$, can be distinguished by immunochemical methods. Proteolysis of a serum acute-phase protein, SAA, is thought to produce protein AA, which is the major constituent of secondary amyloid. Protein AL, similarly derived but from immunoglobulin light chains, is found in primary amyloid, amyloid secondary to multiple myeloma, and the form associated with familial Mediterranean fever. .8-51 $^{48}$

Despite the identification of these different proteins, the pathogenesis of both generalised and localised amyloidosis is unknown. We do not know whether the deposition of protein follows excess production, defective clearance, or a combination of both. $^{48}$ Localised genitourinary and laryngeal amyloid and the only case of localised pulmonary amyloid to be analysed have all shown AL protein. $^{5152}$ The localised forms contain abundant plasma cells and occur in tissues which, as well as being in direct contact with environmental antigens, are the sites of local immunoglobulin production. Thus an abnormality of the local secretory immune system, chronic local antigenic stimulation, local abnormally functioning plasma cells, or increased local vascular permeability for amyloidogenic proteins are possible pathogenetic mechanisms. The fact that the regional lymph nodes may be affected suggests that either the amyloid protein itself or an antigen causing chronic stimulation is transportable in the local lymphatic system.

Pulmonary amyloid is likely to be more common than is generally recognised. It can mimic various diseases and should therefore be thought of when a clinical diagnosis proves difficult to confirm on initial investigation. The classification of amyloidosis is certain to change as more is learnt about its nature and the nature of the protein subunits. At present, however, an anatomical classification such as we have proposed remains useful as an aid to diagnosis and management.

PJ THOMPSON
KM CITRON
Cardiothoracic Institute
London SW3 $6 H P$

\section{References}

1 Glenner GC. Amyloid deposits and amyloidosis: the $\mathrm{B}^{\times}$ fibrilloses. Parts 1 and 2. N Engl J Med 1980; $\infty$ 302:1283-92, 1333-43.

2 Wang CC, Robins LL. Amyloid disease-its roentgen ${ }^{\circ}$ manifestations. Radiology 1956;66:489-501.

${ }^{3}$ Reiman HA, Koucky RF, Ecklund CM. Primary amyloidosis limited to tissue of mesodermal origin. Am J Pathol 1935;11:977-88.

${ }^{4}$ Lesser A. Ein Fall von Enchondroma osteiodes mixtum을 der Lunge mit partieller amyloid Entortung. Virchows Arch (Pathol Anat) 1877;69:404-8.

5 Prowse CB. Amyloidosis of the lower respiratory tract. $\vec{\varphi}$ Thorax 1958;13:308-20.

6 Weiss L. Isolated multiple nodular pulmonary amyloidosis. Am J Clin Pathol 1960;33:318-29.

' Spencer H. Pathology of the lung: excluding tuber-O culosis. 3rd ed. Oxford: Pergamon Press, 1975:67580.

${ }^{8}$ Wilson SR, Sanders DE, Delarue NC. Intrathoraciō manifestations of amyloid disease. Radiology 1976. $\frac{\mathbb{Q}}{\circ}$ 120:283-9.

${ }^{9}$ Himmelfarb E, Wells S, Rabinowitz JG. The radiologiç spectrum of cardiopulmonary amyloidosis. Chest 1977;72:327-32.

${ }^{10}$ Rubinow A, Celli BR, Cohen AS, Rigden BG, Brody JS? Localised amyloidosis of the lower respiratory tract Am Rev Respir Dis 1978;118:603-11.

$"$ Celli BR, Rubinow A, Cohen AS, Brody JS. Patterns ow pulmonary involvement in systemic amyloidosis. Chest: 1978;74:543-7.

12 Teixidor HS, Bachman AL. Multiple amyloid tumours of the lung. Am J Roentgenol 1971;111:525-9.

${ }^{13}$ Lunzenhower K. Uber amyloid "Tumoren" der Lungen? Frankf Z Pathol 1952;63:519-32.

${ }^{14}$ Hayes WT, Bernhardt $\mathrm{H}$. Solitary amyloid mass of the lung. Cancer 1969;24:820-5.

${ }^{15}$ Fenoglio C, Pascal RR. Nodular amyloidosis of the lungs. Arch Pathol 1970;90:577-82.

${ }^{16}$ O'Malley E, Neligan MC, Dempsey JV. Diffuse tracheobronchial amyloidosis. Ir J Med Sci 1971 N 140:343-52.

${ }^{17}$ Loire R, Saugier J, Brune J, Galy P. Ámylose eț tracheobronchopathie osteoplastique à propos de troîs observations. Lyon Med 1978;239:75-8.

${ }^{18}$ Revol L, Mournier-Kuhn P, Paliard P, et al. L'amyloid ose primitive de l'arbre tracheobronchique à propos d'un nouveau cas. Rev Med Lyon 1965;14:583-5.

${ }^{19}$ Sakula A. Tracheobronchopathia osteoplastica. Thora 00 1968;23:105-10.

${ }^{20}$ Alroy GG, Lichtig C, Kaftori JK. Tracheobronchopathiक्ष osteoplastica: end stage of primary lung amyloidosiso Chest 1972;61:465-8. 
${ }^{21}$ Jones AW, Chatterji AN. Primary tracheobronchial amyloidosis with tracheobronchopathia osteoplastica. Br J Dis Chest 1977;71:268-72.

${ }^{22}$ Rejou JJ, Bannier M. Amylose bronchique primitive et tracheopathie chondreosteoplastique. Ouest Med 1978;31:197-201.

${ }^{23}$ Mainwaring AR, Williams G, Knight EO, Bassett HFM. Localised amyloidosis of the lower respiratory tract. Thorax 1969;24:441-5.

${ }^{24}$ Antunes ML, Da Luz JMV. Primary diffuse tracheobronchial amyloidosis. Thorax 1969;24:307-11.

${ }^{25}$ Schottenfield A, Arnold LM, Gruhn JG, Etess AD. Localised amyloid deposition in the lower respiratory tract. Am J Med 1951;11:770-6.

${ }^{26}$ Gordonson JS, Sargent NE, Jacobsen G, Turner F. Roentgenographic manifestations of pulmonary amyloidosis. J Can Assoc Radiol 1972;23:269-72.

${ }^{27}$ Flemming AFS, Fairfax AJ, Arnold AG, Lane DJ. Treatment of endobronchial amyloidosis by intermittent bronchoscopic resection. Br J Dis Chest 1980;74: 183-8.

${ }^{28}$ Kronschnabel EF, Landis FB. Primary amyloid tumour cause of middle lobe syndrome. Arch Otolaryngol 1962;76:233-8.

${ }^{29}$ Cotton RE, Jackson JW. Localised amyloid tumours of the lung simulating neoplasm. Thorax 1964;19:97103.

30 Wichert P. Lungenrundherde als Symptom einer primaren Amyloidose. Thoraxchirgurie 1969;17:113-8.

${ }^{31}$ Desai RA, Mahajan VK, Benjamin S, Van Ordstrand HS, Cordasco EM. Pulmonary amyloidoma and hilar adenopathy. Rare manifestations of primary amyloidosis. Chest 1979;76:170-3.

32 Brauner GJ, Bazzaz FA, Mihm MC. Acquired disease of the skin and solitary amyloidoma of the lung. Am J Med 1974;57:978-86.

${ }^{33}$ Dahlgreen SE, Lewenhaupt A, Ovenfors CO. Fine needle biopsy diagnosis in nodular pulmonary amyloidosis. Acta Pathol Microbiol Scand 1970;78: $1-5$.

34 Bierny JP. Multinodular primary amyloidosis of the lung: diagnosis by needle biopsy. Am J Roentgenol 1978;131:1082-3.

${ }^{35}$ Dyke PC, Demaray MJ, Delavan JW, Rasmussen RA. Pulmonary amyloidoma. Am J Clin Pathol 1973; 61:301-5.

${ }^{36}$ Fitzer PM. Isolated nodular pulmonary amyloidosis. $V A$ Med J 1978;105:53-5.
${ }^{37}$ Zundel WE, Prior AP. An amyloid lung. Thorax 1971;26:357-63.

${ }^{38}$ Sterba J. Metastasirendes bronchial Karzinoid mit Amyloid in Stroma. Z Pathol Pathol Anat 1968; 111:555-61.

${ }^{39}$ Gordon HW, Miller R, Mittman C. Medullary carcinoma of the lung with amyloid stroma: a counterpart of medullary carcinoma of the thyroid. Hum Pathol 1973;4:431-6.

${ }^{40}$ Cain H, Egner E. Metastaserendes, amyloid bildenes Karznome des Apud Systems. Verh Dtsch Pathol Ges 1977;61:314-7.

${ }^{41}$ Hacihanefioglu U, Uzgoren E. Amyloid producing tumour of the lung. Thorax 1981;36:395-6.

${ }^{42}$ Fors B, Ryden L. Tumoral amyloidosis of the lung. Acta Pathol Microbiol Scand 1964;61:1-12.

${ }^{43}$ Beckert W. Bronchialkarzenom bei multiplen bilateralen amyloid Tumoren der Lunge. Z Ges Inn Med 1979;34:127-9.

4 Fournial F, Ravoteur B, Carre JC, Carriere JC, Bollinelli R. Amylose broncho-pulmonaire. Poumon 1979;35: 97-100.

45 Carcia Gallego F, Calleja Canelas JL. Hilar enlargement in amyloidosis. $N$ Engl J Med 1974;291:531.

${ }^{46}$ Engleman P, Liebow AA, Gmelich J, Friedman PJ. Pulmonary hyalinising granuloma. Am Rev Respir Dis 1977;115:997-1008.

${ }^{47}$ Ravid M, Robson M, Keizman IK. Prolonged colchicine treatment for patients with amyloidosis. Ann Intern Med 1977;87:568-70.

${ }^{48}$ Franklin EC. Some unresolved problems in the amyloid diseases. Am J Med 1979;66:365-7.

${ }^{49}$ Isersky C, Ein D, Page D, Harada M, Glenner GG. Immunochemical cross reactions of human amyloid proteins with immunoglobulin light polypeptide chains. J Immunol 1972;108:480-93.

${ }^{50}$ Kisilevsky R, Axelrod M, Corbett W. The role of inflammatory cells in the pathogenesis of amyloidosis. Lab Invest 1977;37:544-53.

${ }^{51}$ Glenner GG, Page DL. Amyloid, amyloidosis and amyloidgenesis. Int Rev Exp Pathol 1976;15:1-89.

52 Page DL, Isersky C, Harada M, Glenner GG. Localised origin of localised pulmonary amyloidosis. Res Exp Med 1972;159:75-86.

53-149 A complete set of references 53-149 has been lodged with the Editor; copies may be obtained by writing to the authors. 